Plant Tissue Cult. \& Biotech. 30(2): 189-197, 2020 (December)

(CBangladesh Assoc. for Plant Tissue Culture \& Biotechnology

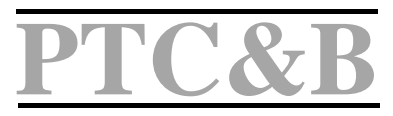

\title{
Asymbiotic Seed Germination of Thunia alba, a Variable Orchid in an Isolated Karst Hill of Xishuangbanna, Yunnan, China
}

\author{
Zi-Yu Zhou, Ju Li, Xi-Hui Peng and Sven Landrein* \\ Xishuangbanna Tropical Botanical Garden XTBG, Horticulture Department, Yunnan, \\ Xishuangbanna, Mengla, Menglun Town, 666303 China \\ Key words: Ex situ conservation, Thunia alba, A variable orchid
}

\begin{abstract}
Asymbiotic seed germination of Thunia alba (Lindley) H.G. Reichenbach was tested on different media in order to propagate and preserve its genetic diversity. In addition different plant hormones were used in the similar germination experiments. Results from these experiments revealed that Knudson medium (KC) had the best germination ability but Mitra and modified Murashige and Skoog (MS) also showed good responses for growth and root formation in the seedling after eight weeks. Coconut water $(\mathrm{CW})$ was the most efficient for promoting germination and growth, addition of $0.046 \mu \mathrm{M}$ and 0.46 $\mu \mathrm{M} \mathrm{Kn}$ also induced better germination rate and formation of leaves. The seedlings after eight months were transferred and acclimatized to grow in the garden on a medium containing bark and crushed concrete blocks. Although the species is amongst the rare orchid species that can successfully propagate asexually in the wild it is demanding for substrate and climatic conditions.
\end{abstract}

\section{Introduction}

Thunia alba (Lindley) H. G. Reichenbach has a wide range of distribution from China, north-east India, Indonesia, Malaysia, Myanmar, Nepal, Thailand and Vietnam (Chen and Wood 2009). Seidenfaden (1986) accepted 4 species based on a preliminary study and five species are listed on the Monocot World Checklist (WCSP 2017), including Thunia alba var. alba, T. alba var. bracteata (Roxb.) N. Pearce \& P. J. Cribb, T. bensoniae Hook. f., T. brymeriana Rolfe, T. candidissima (N.E.Br.) Rchb. f. and T. pulchra Rchb.f. Morphological characters to differentiate the species are based on the colour of the lip that are white or purple with yellow, red, orange or purple markings. Thunia pulchra differs by having 4

*Author for correspondence: <sven@xtbg.ac.cn>.

DOI: https://doi.org/10.3329/ptcb.v30i2.50689 
not 8 pollinia, smaller flowers and a lip with a minute spur (Andre Shuiteman, Pers. Comm.). No recent revision of the genus exists but only Thunia alba is recorded for China (Chen and Wood 2009, Li et al. 2015). In Yunnan the plant is present in Dali, Lincang, Lancang, Pu'er, Wenshan and Xishuangbanna prefectures ranging from 1200 to $2300 \mathrm{~m}$ altitude (Gao et al. 2013). Present collection is from Southeast Xishuangbanna in Mengla county at an elevation of $1000 \mathrm{~m}$, growing on a karst hill. The population in this locality is less than 15 individuals. The population is remarkable by the colour of its labellum, with a yellow centre, orange stripes on the margin and an erose margin (Fig. 1C). Although the actual knowledge in the taxonomy of the genus is insufficient to assign this taxon to any form, this represents an interesting variation for use in horticulture and ex situ conservation and may be linked to a particular distribution pattern within the genus.

Thunia alba is a lithophytic species and is amongst the few orchids that can have an asexual vegetative reproduction by producing new plantlet at the nodes of the fleshy stems (Figs 1D and 2). Node section and rooting is the easiest way to obtain new plants for ex situ programs and is relatively easy when provided with a suitable growing medium. However, it can only produce a limited amount of plants and does not preserve the genetic diversity obtained by using wild pollinated seeds.

Germination of orchid seeds in the wild is difficult without the symbiotic association of the mycorrhizal fungi, therefore asymbiotic seed germination is a valuable technique for ex situ conservation (Arditti and Ernst 1993, Arditti 1967). This represents a valuable technique for propagation and aims at preserving genetic diversity, with good reintroduction and ornamental potentials.

There are a few reports on in vitro germination of seeds in the genus Thunia (Singh et al. 2014), and in addition such requirements are specific and depend on the orchid variety and provenance. In this study authors evaluate the effect of several media composition on the asymbiotic seed germination, protocorm and seedling growth of Thunia alba, from an isolated Karst population in Xishuangbanna.

\section{Materials and Methods}

Yellowish capsules from wild pollinated plants were harvested in Xishuangbanna, Mengla on a Karst hill known for its rich orchid diversity (Gao et al. 2013). Experiments were done in the laboratory of the Horticulture Department, Xishuangbanna Tropical Botanical Garden, Chinese Academy of Science (XTBG, CAS).

The capsules were sterilized by soaking several times in $70 \%$ alcohol for 5 minutes and rinsed with distilled water. The capsules were opened, and seeds were transferred in a syringe where they could be further cleaned with a $2 \%$ sodium hypochlorite solution $(\mathrm{NaOCl})$.

Four media were chosen following Singh et al. (2014), namely Knudson (KC) (1946), Vacin and Went (VW) (1949), Mitra (1976) and Murashige and Skoog (1962), to test for their effectiveness in promoting germination of seeds. MS medium was also tested using 
half strength (half MS) as well as with different concentration of salts (major salts in $1 / 2$ strength and minor salts and organic components in full strength). Three per cent sucrose and $0.8 \%$ agar were added to each medium. $\mathrm{pH}$ was adjusted to 5.8 by adding $0.1 \mathrm{~N}$ $\mathrm{NaOH}$ or $0.1 \mathrm{~N} \mathrm{HCl}$. Each medium was autoclaved at $121^{\circ} \mathrm{C}$ for $20 \mathrm{~min}$. To study the effect of cytokinin in promoting the germination and growth of the seeds and protocorms authors also prepared MS with different concentrations of added cytokinin. Coconut water $(\mathrm{CW})(10,20$ and $30 \% \mathrm{v} / \mathrm{v})$, BAP $(0.044,0.44,4.4$ and $22.0 \mu \mathrm{M})$ and $\mathrm{Kn}(0.046,0.46$, 4.6 and $23.0 \mu \mathrm{M}$ ). Seeds were then transferred to the sterile media under laminar flow

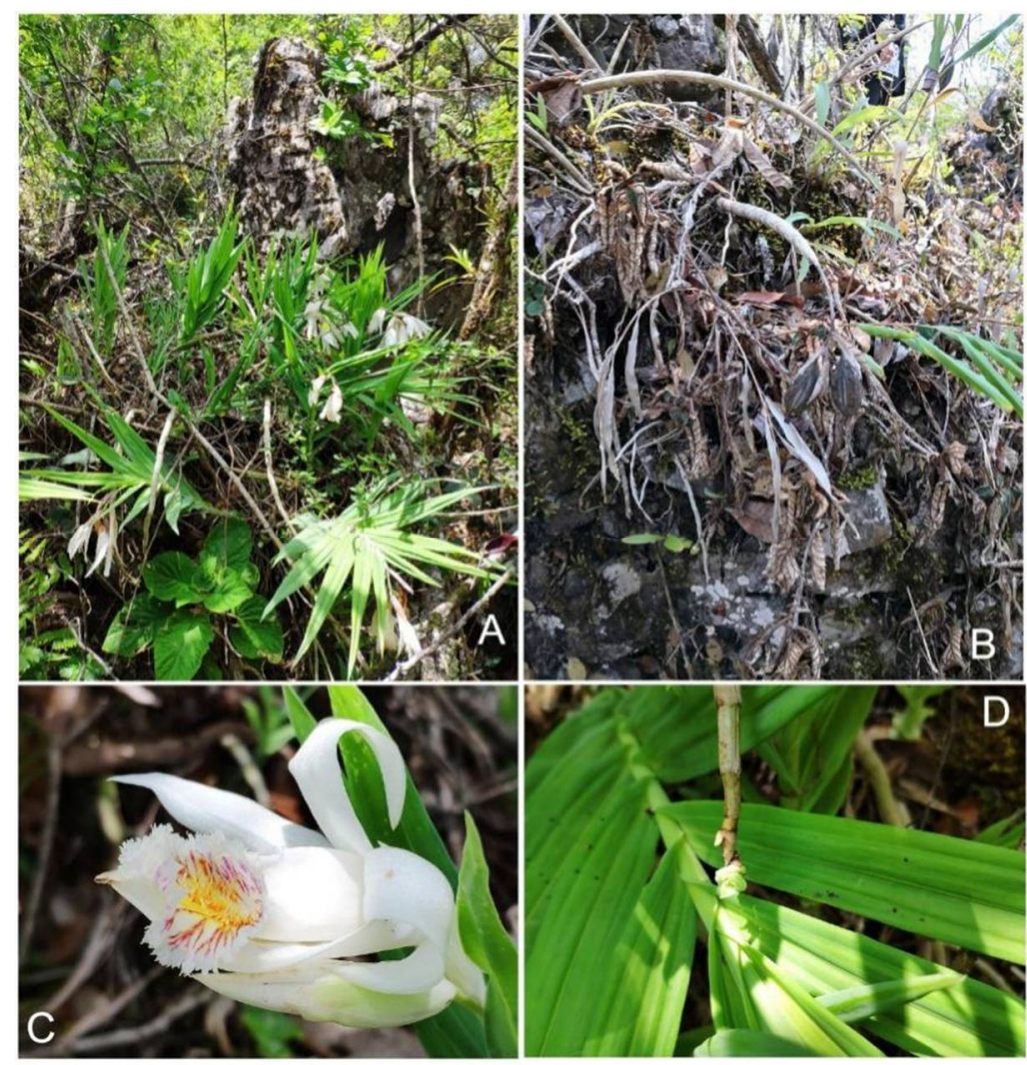

Fig. 1. Thunia alba collected in Xishuangbanna, Mengla, $1000 \mathrm{~m}$ high: A. Flowering plant in July at the beginning of the rainy season. B. Fruiting plant at the end of the rainy season in October. C. Flower showing lip with yellow centre and red/purple stripes on the margin. D. Adventitious plantlet formed on an old stem's node.

and were observed and counted every week for two months. Mitra medium was problematic, because high level of charcoal content made the Petri dishes black and authors were not able to count non germinated seeds under the inverted microscope. For this reason, they only observed germination, protocorm and seedlings stages for this medium. The Petri dishes were transferred into a culture room with a $16 / 8 \mathrm{hrs}$ photoperiod at $25^{\circ} \mathrm{C}$. 
Every treatment had 14 replicates and each experiment was repeated three times. The data were subjected to completely randomized design and analysed using one-way ANOVA statistics and means were compared with the LSD (Snedecor and Cochran 1989).

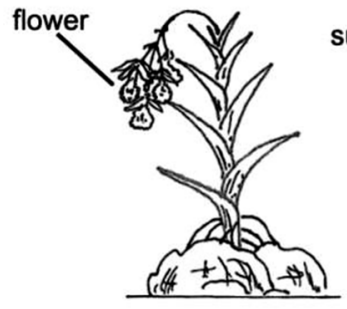

A

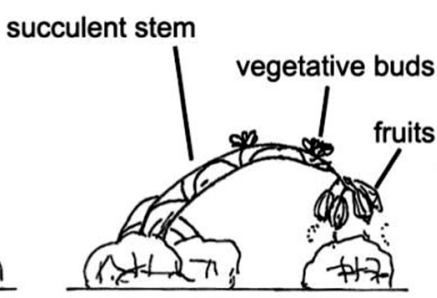

B

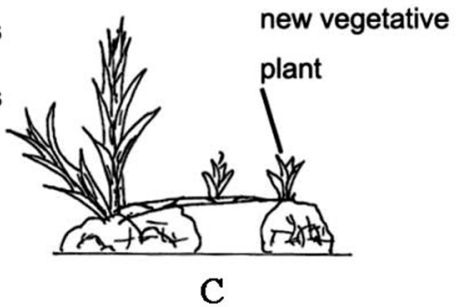

C

Fig. 2. Asexual reproduction of Thunia alba. A. Flowering plant during the rainy season. B. Fruiting plant at the end of the rainy season without leaves. C. Plantlets and roots produced on the nodes of the stem during the dry season.

\section{Results and Discussion}

All media showed more than $60 \%$ germination and Knudson had the highest rate of germination (79.3\%, Table 1). No significant difference between Knudson, MS full and half MS were observed. Seeds elongated after the first week and the first protocorms were produced after 2 weeks on half MS and only after four weeks on Mitra. All seeds swelled to become yellow to green embryo (Fig. 3A) but later all became green coloured protocorms (Fig. 3C). Cilia and roots were initiated at the latest stage after one or two leaves were produced (Figs 3F-G) and were particularly abundant on Mitra. The addition of $20 \%$ coconut water $(\mathrm{CW})$ got the highest rate of germination (Table 2). BAP $0.044 \mu \mathrm{M}$ as well as Kinetin $(0.046$ and $4.6 \mu \mathrm{M})$ also improved germination rate but higher concentration of $\mathrm{CW}$ was not beneficial. $\mathrm{Kn}$ in lower concentration was also beneficial for root formation and size of the seedlings.

Similar study indicated that the protocorms may require 10 months to attain a suitable size prior to acclimatization (Jualang et al. 2014). After ten months, seedlings were approximately $5 \mathrm{~cm}$ long bearing 8 - 10 leaves and more than 5 roots. Seedlings were transferred on a substrate with bark and crushed concrete to recreate the Karst condition in which the species was found growing (Fig. 3H).

Morphological and genetic variation studies within the genus Thunia are lacking thus the number of species is still open for debate (Sudhakar 2013). Conservation work needs good taxonomic systems to be able to preserve most of the diversity. Increasing knowledge on propagation is also a way of preserving this diversity when this basic knowledge is lacking. Thunia alba has a wide distribution range (Chen and Wood 2009), is a variable species and it is often found growing as a lithophytic plant on isolated and disjunct Karst hills. The labellum with a yellow centre, orange stripes on the margin and 
an erose margin is different from similar plants growing in Xishuangbanna (Gao et al. 2013) and more similar to plants named Thunia alba var bracteata (Sudhakar 2013), but this has no yellow markings in the centre of the lip.
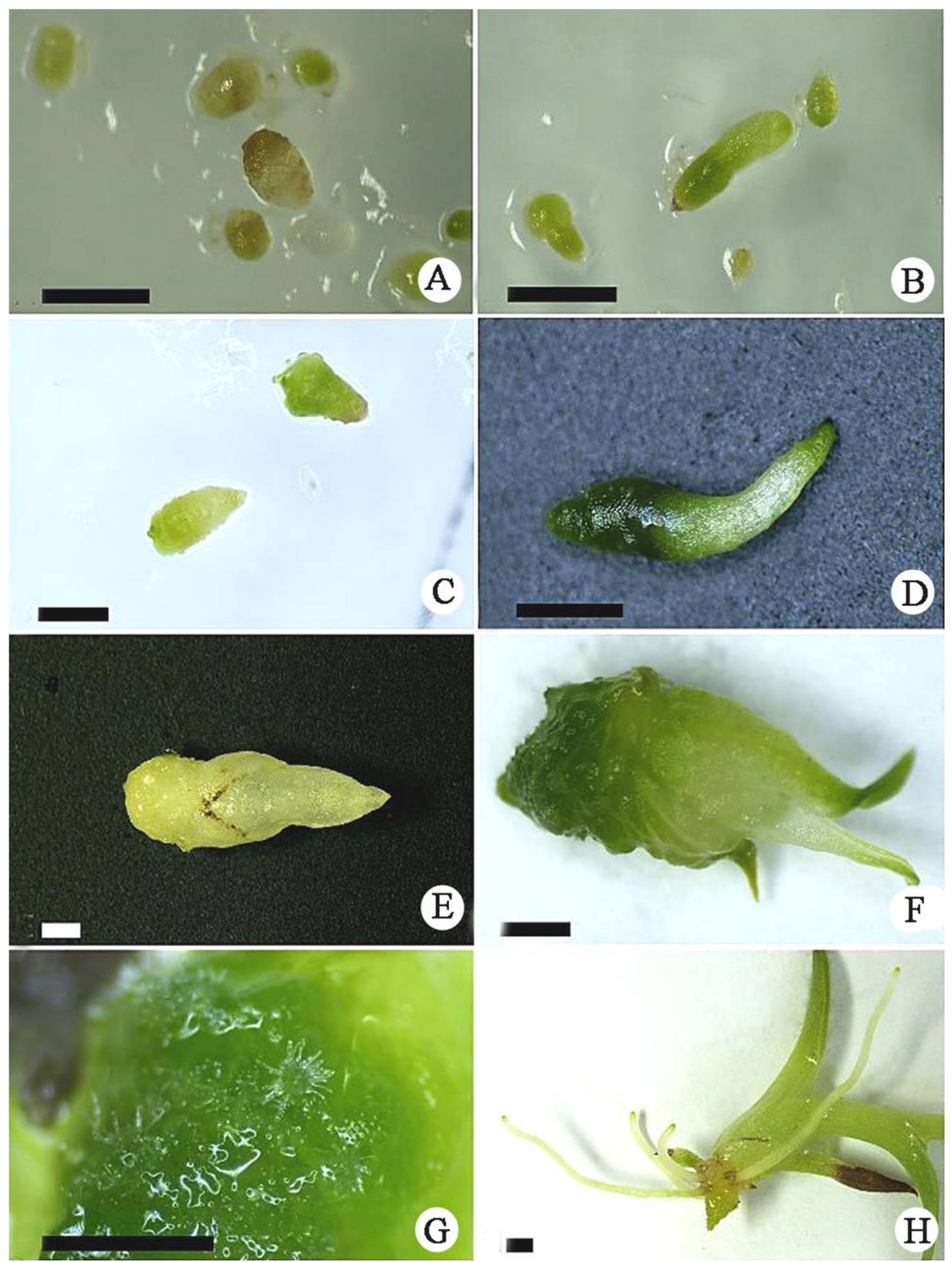

Fig. 3(A-H). Development stage of Thunia alba from seeds to protocorm and seedlings: A. Seeds after two weeks. B. Elongating seeds. C. Protocorm after 4 weeks. D-E. Young seedling. F. First leaves after 8 weeks. G. Papille (roots) forming after 8 weeks. H. Seedling after 4 months. Scale bar $1 \mathrm{~mm}$ in $\mathrm{A}-\mathrm{H}$ 
Table 1. Effect of different media on seed germination and seedling development of T. alba.

\begin{tabular}{lllllll}
\hline Medium & $\begin{array}{l}\text { Percentage } \\
\text { germination } \\
\text { after 8 weeks }\end{array}$ & $\begin{array}{l}\text { Number of } \\
\text { protocorm } \\
\text { after 4 weeks }\end{array}$ & $\begin{array}{l}\text { Number of } \\
\text { protocorm } \\
\text { after 8 weeks }\end{array}$ & $\begin{array}{l}\text { Seedling size } \\
\text { after 8 weeks } \\
(\mathrm{mm})\end{array}$ & $\begin{array}{l}\text { Roots } \\
\text { formation } \\
\text { (Total) }\end{array}$ & $\begin{array}{l}\text { Number of } \\
\text { leaves (if } \\
\text { present) }\end{array}$ \\
\hline Knudson (KC) & $79.3 \pm 13.08 \mathrm{a}$ & $5.06 \pm 4.76$ & $117.36 \pm 27.58$ & $0.87 \pm 0.27$ & 3 & $1.75 \pm 0.5$ \\
Vacin \& Went (VW) & $69.39 \pm 13.04 \mathrm{~b}$ & $8.28 \pm 7.26$ & $77.01 \pm 13.04$ & $1.00 \pm 0.21$ & 0 & - \\
Mitra & $*$ & $0 \pm 0$ & $102.90 \pm 30.28$ & $1.46 \pm 0.46$ & 20 & $1.71 \pm 0.59$ \\
MS Full & $77.3 \pm 9.51 \mathrm{ac}$ & $16.85 \pm 9.16$ & $95.61 \pm 23.27$ & $1.85 \pm 0.68$ & 4 & $1.79 \pm 0.92$ \\
MS (1/2 strenght) & $73.8 \pm 16.51 \mathrm{ab}$ & $25.58 \pm 20.51$ & $108.05 \pm 39.93$ & $1.20 \pm 0.32$ & 6 & $1.57 \pm 0.60$ \\
MS (modified) & $59.75 \pm 17.60 \mathrm{~d}$ & $26.6 \pm 16.96$ & $95.71 \pm 44.13$ & $1.60 \pm 0.47$ & 17 & $1.97 \pm 0.69$ \\
\hline
\end{tabular}

*Indicates counting of non-germinated seeds was not possible.

Table 2. Effect of coconut water (CW) and cytokinin on seed germination and seedling growth of T. alba.

\begin{tabular}{llllllll}
\hline $\begin{array}{l}\text { Growth } \\
\text { regulator }\end{array}$ & $\begin{array}{l}\text { Concen- } \\
\text { tration }\end{array}$ & $\begin{array}{l}\text { Percentage } \\
\text { germination } \\
\text { after } 8 \text { weeks }\end{array}$ & $\begin{array}{l}\text { Number of } \\
\text { protocorm } \\
\text { after 4 weeks }\end{array}$ & $\begin{array}{l}\text { Number of } \\
\text { protocorm } \\
\text { after } 8 \text { weeks }\end{array}$ & $\begin{array}{l}\text { Seedling size } \\
\text { after } 8 \text { weeks } \\
(\mathrm{mm})\end{array}$ & $\begin{array}{l}\text { Roots } \\
\text { formation } \\
\text { (Total) }\end{array}$ & $\begin{array}{l}\text { Number of } \\
\text { leaves (if } \\
\text { present) }\end{array}$ \\
\hline $\mathrm{CW}$ & $10 \%$ & $75.67 \pm 10.14 \mathrm{ab}$ & $21.05 \pm 8.25$ & $100.31 \pm 32.36$ & $1.00 \pm 0.24$ & 0 & $1.12 \pm 0.35$ \\
& $20 \%$ & $76.1 \pm 15.0 \mathrm{a}$ & $15.03 \pm 6.04$ & $90.86 \pm 24.74$ & $0.98 \pm 0.32$ & 2 & $1.25 \pm 0.58$ \\
& $30 \%$ & $60.88 \pm 18.14 \mathrm{c}$ & $12.6 \pm 5.37$ & $64.61 \pm 29.31$ & $0.99 \pm 0.31$ & 1 & $1.15 \pm 0.55$ \\
$\mathrm{BAP}$ & $0.044 \mu \mathrm{M}$ & $70.67 \pm 14.07 \mathrm{ab}$ & $10.43 \pm 4.21$ & $70.65 \pm 16.10$ & $1.37 \pm 0.42$ & 10 & $1.68 \pm 0.58$ \\
& $0.44 \mu \mathrm{M}$ & $61.99 \pm 14.34 \mathrm{c}$ & $5.03 \pm 2.87$ & $79.08 \pm 24.95$ & $1.22 \pm 0.81$ & 2 & $1.20 \pm 0.42$ \\
& $4.4 \mu \mathrm{M}$ & $66 \pm 14.36 \mathrm{bc}$ & $5.45 \pm 3.62$ & $68.25 \pm 18.24$ & $1.49 \pm 0.75$ & 1 & $1.28 \pm 0.47$ \\
& $22 \mu \mathrm{M}$ & $57.06 \pm 13.97 \mathrm{c}$ & $3.76 \pm 2.63$ & $64.57 \pm 18.60$ & $0.83 \pm 0.24$ & 0 & $1.10 \pm 0.32$ \\
$\mathrm{Kn}$ & $0.046 \mu \mathrm{M}$ & $71.08 \pm 9.97 \mathrm{ab}$ & $16.06 \pm 14.10$ & $84.03 \pm 14.82$ & $1.91 \pm 0.75$ & 21 & $2.07 \pm 0.53$ \\
& $0.46 \mu \mathrm{M}$ & $69.75 \pm 9.26 \mathrm{~b}$ & $27.10 \pm 22.47$ & $76.61 \pm 17.84$ & $1.62 \pm 0.71$ & 19 & $2.41 \pm 0.50$ \\
& $4.6 \mu \mathrm{M}$ & $70.38 \pm 8.63 \mathrm{ab}$ & $6.44 \pm 4.87$ & $88.03 \pm 15.42$ & $1.17 \pm 0.60$ & 12 & $1.81 \pm 0.60$ \\
& $23 \mu \mathrm{M}$ & $69.29 \pm 10.02 \mathrm{bd}$ & $5.0 \pm 4.11$ & $88.92 \pm 22.45$ & $0.85 \pm 0.24$ & 3 & $1.40 \pm 0.51$ \\
\hline
\end{tabular}

Due to their specialized biology, it is difficult to germinate orchid seeds and obtain enough viable plantlets for re-introduction in the wild. Knudson (1922) made it possible for orchid seeds to be germinated asymbiotically and to produce plants for ex situ conservation. Asymbiotic seed germination can be an efficient way to reproduce orchids from seeds and overcome the problem of ectomycorrhizal association in the wild. This study shows that this technique is successful when applied on Thunia alba and is an essential tool to preserve the population and genetic diversity of this species. Similarly, a study of in vitro multiplication of Thunia marshalliana (Singh et al. 2014) also found the genus to respond well to asymbiotic seed germination. Though they found that modified MS and addition of $10 \%$ coconut water resulted in the best germination and addition of cytokinin had no effect. Here, it was also found that addition of coconut water was the 
most beneficial, but Knudson medium had a non-significant higher germination rate than modified MS. KC medium was first developed to increase germination success of orchids seeds (Curtis and Spoerl 1948) and often used for tropical epiphytic orchids (Arditti 1982). KC medium has little macro- and micro-salts and no vitamins.

Different media were chosen because their composition of mineral salts, nitrogen, organic compounds, and vitamin were different. Nitrogen concentration can influence orchid seed germination (Stewart and Kane 2006). Mitra, KC and VW contain inorganic sources of nitrogen whereas MS contains inorganic and organic sources of nitrogen (amino acid). All media showed good germination rate suggesting that both organic and inorganic source of nitrogen were used by the seeds. Nevertheless, addition of low concentration of $\mathrm{CW}$ increased germination success, suggesting addition of other organic compounds present in CW enhanced germination, as shown in several studies on orchid germination (Arditi and Ernst 1984).

There are some reports showing the inhibitory effects of various cytokinins on the asymbiotic germination of orchids (Stewart and Kane 2006). But other studies suggest plant growth regulators (PGR) have a positive effect on seed germination (Mathews and Rao 1980, Kishor et al. 2006). The production of auxin-like symbiotic fungus such as mycorrhizal Rhizopogon roseolus (Hadley and Harvais 1968) facilitates seed germination. This fact can explain the roles of exogenous plant growth regulators in asymbiotic seed germination (De Pauwet al. 1995, Lo et al. 2004). Present samples showed a better germination with $0.046 \mu \mathrm{M}$ and $0.46 \mu \mathrm{M} \mathrm{Kn}$ but the other PGRs had no effect or were detrimental to the germination, showing that these act differently under different conditions.

In conclusion asymbiotic seed germination of Thunia alba can ensure a better production of large quantity of genetically diverse seedlings that can be used for ex situ conservation. With this experiment present authors obtained more than 100 plants in 8 months. However, the medium used for asymbiotic germination and seedling development requires more components than that for symbiotic germination, such as organic and inorganic available carbon sources as well as PGRs (Temjensangba and Deb 2005). Nitrogen as well as some cytokinin in the right concentration are essential to produce numerous and healthy seedlings.

It is hoped that using the right medium and suitable protocol for acclimatization will allow the gardeners to grow large quantity of genetically diverse Thunia that can be used for conservation project as well as promoting the importance of Karst in the evolution of orchids.

\section{Acknowledgment}

The present study was supported by the Horticulture Department, Xishuangbanna Tropical Botanical Garden, Chinese Academy of Science. 


\section{References}

Arditti J (1967) Factor effecting the germination of orchid seeds. Bot. Rev. 33: 1-97.

Arditti J (1982) Orchid seed germination and seedling culture, A manual. In: Arditti J (ed.) Orchid biology: Reviews and perspectives. Vol. 2. New York: Cornell University Press. pp. 243-293.

Arditti J and Ernst R (1984) Physiology or germinating orchid seeds. In: Arditti J (ed.) Orchid biology: Reviews and perspectives Vol. 3. New York: Cornell University Press, pp. 177-222.

Arditti J and Ernst R (1993) Micropropagation of orchids. New York: John Wiley \& Sons.

Chen QX and Wood JJ (2009) Thunia. In: Raven PH, Wu ZY, Hong DY (eds.) Flora of China. Vol. 25, Orchidaceae. Science Press, St. Louis, Missouri Botanical Garden Press, Beijing.

Curtis JT and Spoerl E (1948) Studies on the nitrogen nutrition of orchid embryos, comparative utilization of nitrate and ammonium nitrogen. AOS 17: 111.

De Pauw MA, Remphrey WR and Palmer CE (1995) The cytokinin preference for in vitro germination and protocorms growth of Cypripedium candidum. Ann. Bot. 75: 267-275.

Gao JY, Liu Q, Yu DL and Zhu B (2013) Orchids of Xishuangbanna diversity and conservation. Tushu zai banna mu.

Hadley G and Harvais G (1968) The effect of certain growth substances on asymbiotic germination and development of Orchis purpurella. New Phytol. 67: 441-445.

Jualang AG, Devina D, Hartinie M, Sharon JS and Roslina J (2014). Asymbiotic seed germination and seedling development of Vanda dearie. Malays. Appl. Bio. 43(2): 25-3.

Kishor R, Sha Valli Khan PS and Sharma GJ (2006). Hybridization and in vitro culture of an orchid hybrid Ascocenda Kangla. Sci.Hortic.108: 66-73.

Knudson L (1922) Non-symbiotic germination of orchid seeds. Bot. Gaz.73: 1-25.

Knudson L (1946). A new nutrient solution for the germination of orchid seed. AOS 15:214-217.

Li L, Ye DP, Niu M, Yan HF, Wen TL and Li SJ (2015) Thuniopsis: A new orchid genus and phylogeny of the tribe Arethuseae (Orchidaceae). PLoS ONE 10(8):

Lo SF, Satish MN, Kuo CL, Chen CL and Tsay HS (2004) Asymbiotic germination of immature seeds, plantlets development and ex vitro establishment of plants of Dendrobium tosaense makin O-A medicinally important orchid. In Vitro Cell Dev-Pl 40(5): 528-535.

Mathews VH and Rao PS (1980) In vitro multiplication of Vanda hybrids through tissue culture technique. Plant Sci. Lett. 17(3): 383-389.

Mitra GC, Prasad RN and Roychoudhary A (1976) Inorganic salt and differentiation or protocorms in seed callus of an orchid (Dendrobium fimbriatum) and correlated changes in its free acid content. Indian J. Exp. Biol. 14: 350-351.

Murashige T and Skoog F (1962) A revised medium for rapid growth and bioassays with tobacco tissue cultures. Physiol. Plant. 15: 473-497.

Roy AR, Patel RS, Patel VV, Sajeev S and Deka BC (2011) Asymbiotic seed germination, mass propagation and seedling development of Vanda coerulea Griff ex. Lindl. (Blue Vanda): An in vitro protocol for an endangered orchid'. Sci. Hortic. 128: 325-331.

Seidenfaden G (1986) Orchid genera in Thailand XIII. Epidendroid genera. Opera Bot. 89: 10-15.

Singh M, Kumaria S and Tandon P (2014) In vitro multiplication of Thunia marshalliana Rcbh. through mature seeds and pseudonodes. Indian J. Biotechnol. 13: 268-273.

Snedecor GW and Cochran WG (1989) Statistical methods. Iowa University Press, Iowa, USA. 
Stewart SL and Kane ME (2006) Asymbiotic seed germination and in vitro seedling development of Habenaria macroceratitis (Orchidaceae), a rare Florida terrestrial orchid. Plant Cell Tiss. Org. 86: 147-158.

Sudhakar Reddy C (2013) A note on the taxonomy and distribution of Thunia alba var. bracteate (Orchidaceae) in India. Zoo's Print J. 9: 23-25.

Temjensangba T and Deb CR (2005) Regeneration of plantlets from in vitro raised leaf explants of Cleisostoma racimeferum Lindl. Indian J. Exp. Biol. 43: 377-381.

Vacin EF and Went FW (1949) Some pH changes in nutrient solutions. Bot. Gaz. 110: 605-613.

WCSP (2019) World Checklist of Selected Plant Families. Facilitated by the Royal Botanic Gardens, Kew. Published on the Internet; http://wcsp.science.kew.org/Retrieved on 15/07/2019.

(Manuscript received on 7 August, 2020; revised on 24 September, 2020) 